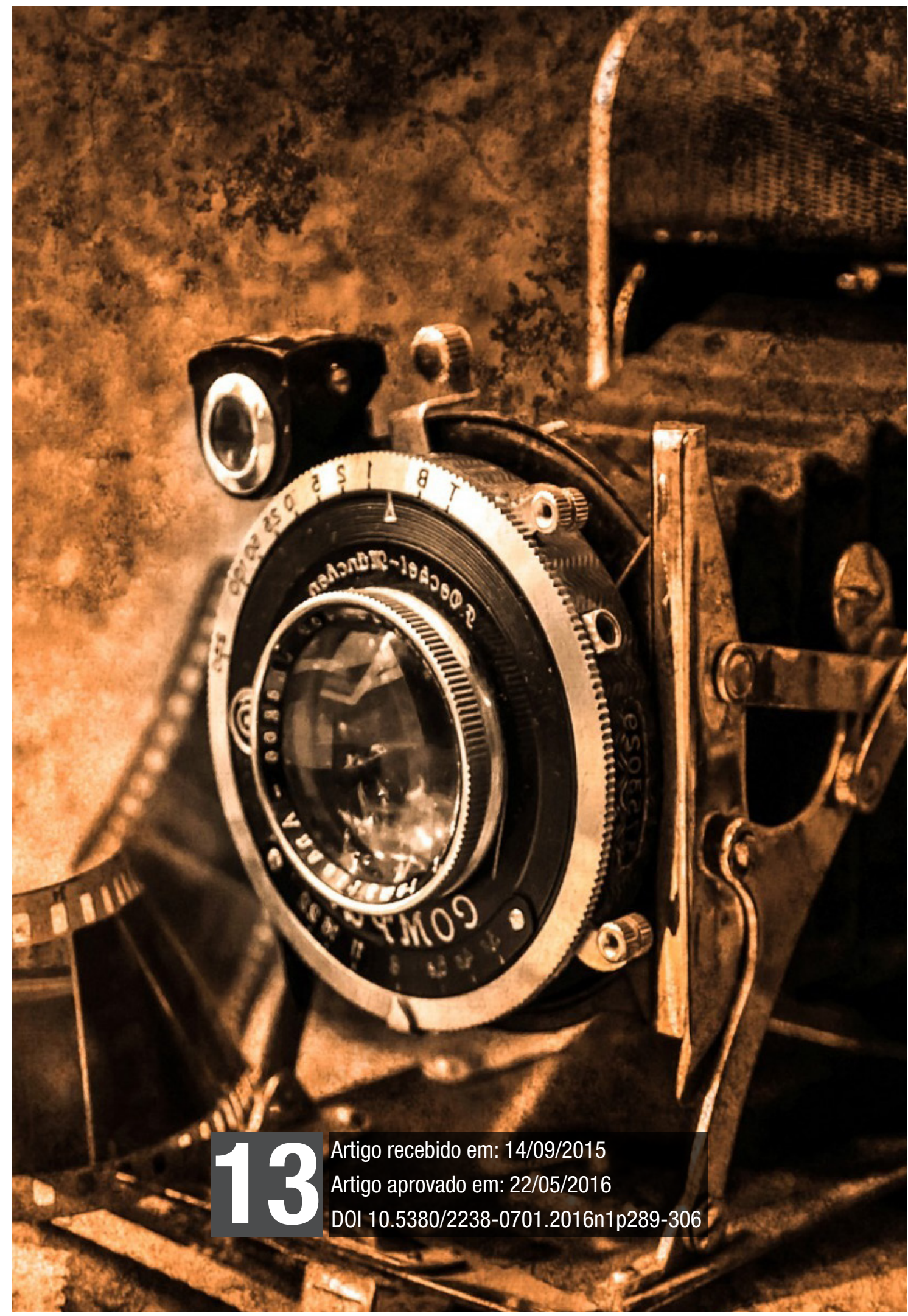


História do Jornalismo. Processos históricos.

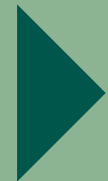




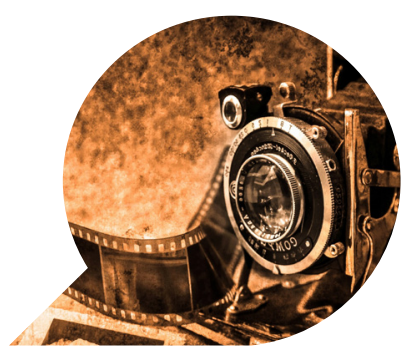

\title{
Um olhar sobre o passado: tensionamentos na pesquisa em História do Jornalismo*
}

\author{
A look into the past: tensions in \\ research in History of Journalism
}

Una mirada sobre el pasado: tensiones en a investigación en Historia del Periodismo

\section{CRISTIANO ANUNCIAÇÃO **}

Resumo: O entrecruzamento entre história e jornalismo gera uma série de tensionamentos na pesquisa em história do jornalismo. No vínculo entre esses dois campos, identificamos, primeiramente, o problema de identidade que pode viver o pesquisador do jornalismo. Afinal, ao debruçar-se sobre o passado, faria ele uma historiografia ou efetivamente uma pesquisa nesta subárea da Comunicação? O modo como o pesquisador lida com tal questionamento interfere na sua relação com o objeto de estudo. Daí, como evidenciar as diversas formas de fazer jornalismo (processos jornalísticos) e as características do contexto analisado (processos históricos)? Este trabalho visa, portanto, discutir essas questões

\footnotetext{
** Jornalista; doutorando em Comunicação (UnB); mestre em Jornalismo (UFSC); e graduado em Comunicação Social/Jornalismo (UESB). E-mail: crisanun@gmail.com
} 
e buscar pistas que possam auxiliar o pesquisador que realiza uma história do jornalismo. Uma hipótese que aparece aqui é que os produtos jornalísticos têm muito a dizer sobre os processos jornalísticos, bem como os processos históricos.

Palavras-chave: História do jornalismo; Processos históricos; Processos jornalísticos; Produtos jornalísticos; Teoria do jornalismo.

\begin{abstract}
The intersection between history and journalism generates a lot of tensions in research in history of journalism. The link between these two fields makes us identify, first, the identity problem that may live the journalism researcher. At last, to look into the past, would he make a historiography or effectively research in this Communication subarea? The way the researcher handles such questioning interferes in his relationship with the study object. Then, how to evidence the different ways doing journalism (journalistic processes) and analyzed context characteristics (historical processes)? This paper therefore aims to discuss these issues and seek clues that might help the researcher who conducts a history of journalism. A hypothesis raised here is that the journalistic products have much to say about journalistic and historical processes.
\end{abstract}

Keywords: History of journalism; Historical processes; Journalistic processes; Journalistic products; Journalism theory.

Resumen: La intersección entre la historia y el periodismo genera una serie de tensiones en la investigación en historia del periodismo. En el vínculo entre estos dos campos, identificamos, en primer lugar, el problema de la identidad experimentada por el investigador del periodismo. Después de todo, a mirar hacia el pasado, él haría una historiografía o efectivamente la investigación en esta subárea de la Comunicación? La forma en que el investigador maneja tal cuestionamiento interfiere en su relación con el objeto de estudio. Por lo tanto, como evidenciar las diversas formas de hacer periodismo (procesos periodísticos) y las características del contexto analizado (procesos históricos)? Este trabajo pretende, por tanto, discutir estos temas y buscar 
pistas que podrían ayudar al investigador que lleva a cabo una historia del periodismo. Una hipótesis que aparece aquí es que los productos periodísticos tienen mucho que decir acerca de los procesos periodísticos y procesos históricos.

Palabras-clave: Historia del periodismo; Procesos históricos; Procesos periodísticos; Productos periodísticos; Teoría del periodismo. 


\section{Introdução}

A relação que a história mantém com as outras áreas das ciências sociais e humanas pode gerar um problema de identidade no pesquisador, caso seu território de origem não tenha um forte alicerce teórico-epistemológico. Essa é a situação do campo de pesquisa do jornalismo, que ainda busca compor suas bases conceitual, teórica e metodológica, de maneira que possa estabelecer um estatuto próprio dentro da sua matriz científica, a área da Comunicação.

Ao pensar o entrecruzamento da história com o jornalismo (ANUNCIAÇÃO, 2015), nos deparamos com alguns problemas na relação entre as diversas formas do fazer jornalístico (processos jornalísticos) e as características do contexto estudado (processos históricos). O primeiro deles faz emergir uma questão fundamental (de onde partimos para desenvolver este trabalho) para esta subárea da Comunicação. Afinal de contas, ao debruçar-se sobre o passado, o estudioso desse domínio faria uma historiografia ou efetivamente uma pesquisa em jornalismo?

Outros questionamentos aparecem daí... Como os estudos em jornalismo dialogam com a história? Onde termina a historiografia e começa a pesquisa em jornalismo? Como a prática jornalística é evidenciada historicamente? Se conseguirmos encontrar pistas em favor do campo de pesquisa do jornalismo, alguns "obstáculos epistemológicos” (BACHELARD, 1996, 2006) que insistem em marcar esses estudos tendem a ser superados nos seus estudos, nas suas teorizações.

Neste texto, buscaremos refletir sobre essas questões, juntandonos a estudiosos que concentram esforços na história da comunicação ${ }^{1}$ (BARBOSA, 2007; MARTINO, 2005, 2008) e nos que trabalham precisamente com história do jornalismo (BARBOSA, 2013; BARBOSA; RIBEIRO, 2005; PONTES, 2008, 2010, 2012). Faremos, então, o seguinte percurso metódico: primeiro, uma discussão a respeito das fronteiras entre a historiografia e a pesquisa em jornalismo, a fim de saber qual o papel do comunicólogo na escrita da história do jornalismo; e em seguida, examinar as relações entre os processos jornalísticos e os processos históricos, e, com isso, contribuir com este campo de pesquisa.

\footnotetext{
${ }^{1}$ Compreendemos a história do jornalismo como parte constituinte da história da comunicação.
} 


\section{Entre a historiografia e a pesquisa em jornalismo}

Se a história - como indica o conceituado historiador francês Paul Veyne (2008) na obra Como se escreve a história e Foucault revoluciona a história - não tem método e nem é ciência ${ }^{2}$ (em relação ao modelo científico clássico), essa condição pode se estabelecer de modo bem mais embaraçoso para a história do jornalismo. Isto porque o campo de pesquisa do jornalismo, que também demanda para si o estudo ${ }^{3} \mathrm{da}$ história do jornalismo, ainda se esforça para constituir um estatuto próprio dentro da sua matriz científica, a área da Comunicação.

Como resultado de uma soma, o percurso da história é definido por entrecruzamentos ('história da sociedade', 'história da política', 'história da economia, 'história da cultura', 'história da ciência' etc.). É possível dizer que tudo tem uma história, mas caso seja retirado esse "tudo", a história se desfaz (PONTES, 2008)4. A história, por esse motivo, "possui sua possibilidade de existência em um 'de' que lhe acompanha e polariza suas relações” (PONTES, 2008, p. 169).

Isso nos leva a acreditar que, na história do jornalismo, essa tênue fronteira gera certa crise de identidade (mesmo que inconsciente) no pesquisador do jornalismo. Estaria ele fazendo uma pesquisa historiográfica ou um estudo teórico em jornalismo? Em alguns momentos, ele se coloca como historiador, cuja autoridade lhe é dada pela primeira área de conhecimento e uma espécie de "mãe de todas as ciências do homem" (FOUCAULT, 1966, p. 476). Em outros, se diz comunicólogo, reivindicando um lugar de fala nas ciências sociais e humanas.

Tomar a posição de pesquisador em jornalismo é, conforme Felipe Pontes (2008), ainda mais complicado, já que a correspondência mais comum a essa identidade o leva à sua prática profissional, devido a pouca tradição em sua prática científica. Tal comportamento é bastante problemático para esse campo de pesquisa. Ao deslocar-se da atribuição que lhe cabe, o pesquisador passa a se relacionar com o objeto de estudo do mesmo modo que o jornalista (repórter, geralmente) faz seu trabalho na redação ou via mercado editorial.

\footnotetext{
${ }^{2}$ Esse status não representa um problema para a história. Pelo contrário, é sua potencialidade. Segundo P. Veyne (2008, p. 18), a história é uma narrativa de eventos, conhecimento por meio de documentos. Sua narração situa-se para além dos documentos, visto que nenhum deles pode ser o próprio evento.

${ }^{3}$ Como bem nota Richard Romancini (2007), já existe um corpus de história do jornalismo, que provém tanto de historiadores quanto de pesquisadores da Comunicação.

${ }^{4} \mathrm{O}$ pesquisador pensa a partir do raciocínio de P. Veyne (2008).
} 
Então, tendemos a ver - equivocadamente, em nosso ponto de vista - apresentado como resultado de uma pesquisa acadêmica em jornalismo a elaboração de perfis e biografias de pessoas, além de trabalhos sobre empresas de mídia, períodos históricos etc. Contudo, mesmo que desfrutem de ótima qualidade editorial (na apuração, na escrita, nas proposições deontológicas da profissão de jornalista etc.), esses produtos são de outra natureza (da prática profissional). Eles podem, obviamente, ser excelentes objetos de análise ou referência bibliográfica, mas não se configuram (ou, pelo menos, não deveriam) como trabalho final de uma pesquisa científica em jornalismo (artigo científico, dissertação de mestrado e/ou tese de doutorado). Mencionamos abaixo algumas dessas pesquisas realizadas sob a tutela acadêmica:

\begin{tabular}{|c|c|}
\hline Tipo de pesquisa & Tema \\
\hline $\begin{array}{c}\text { Jornalistas conhecidos por } \\
\text { seus atributos profissionais } \\
\text { notáveis }\end{array}$ & $\begin{array}{c}\text { Especialmente repórteres } \\
\text { renomados, como João do Rio, Caco } \\
\text { Barcellos, Eliane Brum }\end{array}$ \\
\hline $\begin{array}{c}\text { Produtos jornalísticos mais } \\
\text { longevos ou considerados } \\
\text { como sendo de qualidade } \\
\text { editorial }\end{array}$ & $\begin{array}{c}\text { Repórter Esso, Manchete (revista), } \\
\text { Jornal Nacional }\end{array}$ \\
\hline $\begin{array}{c}\text { Empresas que têm um público } \\
\text { considerável (em termos } \\
\text { de audiência e/ou alcance } \\
\text { territorial) ou bastante } \\
\text { criticadas pelas suas atuações }\end{array}$ & $\begin{array}{c}\text { Rede Globo, Folha de S. Paulo } \\
\text { (as relações marcadamente } \\
\text { controversas dessas empresas com a } \\
\text { ditadura militar) }\end{array}$ \\
\hline $\begin{array}{c}\text { Períodos importantes na } \\
\text { política e na economia }\end{array}$ & $\begin{array}{c}\text { Governo de presidentes brasileiros, } \\
\text { ditadura militar, planos econômicos }\end{array}$ \\
\hline Gêneros jornalísticos & $\begin{array}{c}\text { Fotojornalismo na revista O } \\
\text { Cruzeiro, reportagem na revista } \\
\text { Realidade }\end{array}$ \\
\hline Práticas segmentadas & Imprensa alternativa, jornalismo \\
& feminino \\
\hline
\end{tabular}

Tabela 1: Trabalhos em história do jornalismo. Fonte: elaboração própria. 
Em continuidade ao debate, destacamos a ligação direta que o jornalista tem, em sua prática profissional, com o presente, o imediato, o agora. Essa relação com o tempo é diferente do que ocorre com o estudioso da história do jornalismo. Mesmo que o propósito do pesquisador em jornalismo seja entender o presente (como a teoria e a prática jornalística são organizadas na atualidade), o olhar dele é direcionado para o passado.

O estudo das diferentes formas de manifestação do jornalismo ao longo dos séculos possibilita o exercício de suspensão do presente, uma vez que nem sempre o jornalismo foi do jeito que é atualmente. O exercício crítico do passado descaracteriza teorias que evidenciam exclusivamente a descrição, que apontam categorias da atualidade como regras para descrever todo o jornalismo independente do contexto e do tempo (PONTES, 2010, p. 18).

Essa situação leva o território de pesquisa do jornalismo a ir de encontro ao caminho percorrido pelos outros campos das ciências sociais e humanas. Quando se exime da discussão em torno do seu lugar de fala, ou melhor, suas bases conceitual, teórica e metodológica, o jornalismo deixa que outros campos do conhecimento alcancem maior relevância na reflexão sobre os fenômenos jornalísticos. É importante dizer que não há nenhum problema nisso, já que podemos fazer perguntas diferentes a respeito dos mesmos fenômenos (GROTH, 2006, 2011).

Entretanto, os aspectos que interessam à área da Comunicação diferem dos enfoques da Psicologia, da Sociologia e da Linguística, dentre outras, quando estas elegem o jornalismo como objeto de suas análises. Além disso, os processos jornalísticos ao serem investigados pelos diversos campos do saber, vão se preocupar em responder questões teóricas relacionadas a seus territórios de origem, não ao jornalismo - como um fenômeno comunicacional.

Esse problema se coloca mais fortemente no caso da história do jornalismo. É que o objeto de estudo tende se tornar ainda mais difuso para este pesquisador quando, combinado a estratégias teórico-metodológicas de outros campos do saber, desmembra-se em 'história social do jornalismo', 'história econômica do jornalismo' e 'história política do jornalismo', necessidade que pode ser explicada - como uma hipótese - pela dupla abertura estabelecida pela associação de história 
e jornalismo (PONTES, 2008), pois abrem espaço um para o outro e ainda dão passagem para um terceiro campo do conhecimento.

Para avançarmos na discussão, é preciso entender o papel da história na prática de pesquisa em jornalismo. Há que estar claro para o comunicólogo que levar em conta a história, "não é necessariamente realizar estudos históricos, mas se valer da teoria da história para empreender a análise" (BARBOSA, 2005, p. 53), invertendo, dessa maneira, a lógica do historiador, que busca apreender "o contexto social, político, econômico, em primeiro lugar, e ao qual se soma os periódicos, por exemplo" (BARBOSA, 2013, p. 5, grifo nosso). Nesse caso, para o pesquisador da Comunicação, a centralidade é o fenômeno jornalístico, enquanto o contexto social, político e econômico - muito importante para caracterizar e enriquecer o objeto de estudo - aparecem em segundo plano.

Ao fazer a história do jornalismo, o pesquisador não pode dispensar a apreciação de seus conceitos fundamentais (jornalismo, meio de comunicação, comunicação etc.), tal como afirma Luiz C. Martino (2008) ao fazer um exame crítico da literatura sobre história da comunicação. A reflexão do autor nos dá subsídios para entender o jornalismo - como o conhecemos até os dias de hoje -, como meios de comunicação que emergiram no século XIX, conformados a partir da ascensão da modernidade e do surgimento do capitalismo, com a sociedade urbana, industrial e, cada vez mais, globalizada.

Em termos epistemológicos, é a partir daqui que distinguimos historiografia (grosso modo, o estudo do social em suas variadas dimensões) e história do jornalismo (análise de uma prática social singular na história). Sem essa compreensão, a história do jornalismo apareceria apenas como uma nova nomenclatura para algo que já encontramos por toda parte - seguindo ainda o pensamento de L. C. Martino (2005) acerca da história da comunicação - e que pode ser chamada de 'história da civilização', 'história das relações sociais', 'história do comércio', 'história do consumo', 'história da vida privada' etc.

Em última instância, o que se encontra em jogo são duas compreensões em relação aos meios de comunicação: para o historiador, trata-se da via pela qual são gerados os documentos que dão acesso ao passado, enquanto que, para o comunicólogo, os meios de comunicação dizem respeito às tecnologias que geram uma matriz social (a 
atualidade mediática, esfera pública, cultura do presente...), modificam a experiência social e, portanto, a própria categoria de tempo e a noção de historicidade (MARTINO, 2008, p. 29).

Essa concepção marca a diferença de perspectiva entre o historiador e o comunicólogo (o pesquisador do jornalismo, especificamente), além de discorrer sobre uma nova prática social que possibilita - a partir de um determinado momento na história - uma mudança no modo como as pessoas se relacionam. Nesse sentido, levar em consideração a emergência histórica (demarcação temporal) dos fenômenos jornalísticos suscita implicações conceituais, teóricas e metodológicas para este campo da pesquisa.

$O$ pesquisador que desconsidera essa premissa cai no engano de imputar ao jornalismo (bem como a seus processos e produtos) uma existência em relação a determinado período histórico que essa prática ainda não dispunha, como faz o pesquisador português Jorge Pedro Sousa (2008) no minucioso inventário Uma história breve do jornalismo no ocidente, por exemplo, ao fixar a gênese da atividade jornalística na antiguidade clássica (delimitada por ele como pré-jornalismo) ou as actas romanas como os primeiros "jornais".

No livro Iniciação à filosofia do jornalismo, o brasileiro Luiz Beltrão (1960) trabalha em uma lógica semelhante a de J. P. Sousa. Nele, o autor amplia - digamos assim - sua concepção de jornalismo e situa a atividade como sendo anterior, inclusive, à história. De acordo com ele, o homem primitivo ainda não conhecia a escrita, mas já fazia jornalismo, "o que vale a dizer que transmitia aos seus semelhantes, à sua tribo, com regularidade e frequência, interpretando-os, os fatos correntes que interessavam à comunidade" (BELTRÃO, 1992, p. 33-34).

Tais ilustrações nos dão pistas para pensar a atividade jornalística em relação ao percurso histórico: o jornalismo nem sempre existiu na história da humanidade e não pode ser confundido com alguma outra prática social anterior ao seu surgimento (seja ela política, religiosa ou artística). Essa visão faz com que o pesquisador - ao compreender o jornalismo em sua dimensão histórica - passe a revisitar, em uma perspectiva crítica, os objetos de análise que envolvem sua região de entorno (tais como o entendimento de fato, acontecimento, notícia, reportagem, nota, editorial, jornal, telejornal, repórter, editor etc.). 


\section{Os processos jornalísticos e os processos históricos}

Nas pesquisas históricas, os produtos jornalísticos têm valor de documento. O que se examina, como pesquisador, são apenas vestígios deixados por fontes inesgotáveis (no caso das fontes de mídia, temos a página de jornal, a capa de revista, a entrevista em programa de rádio ou televisão, a carta escrita pelo leitor, a fotografia etc.), uma vez que - como certifica o filósofo alemão Walter Benjamin (1987) articular historicamente o passado não quer dizer conhecê-lo como de fato aconteceu, e sim apropriar-se de uma parte fragmentada dos acontecimentos, visto que não há uma mera reprodução dos eventos, mas uma interpretação deles.

Assim, se impõe como uma necessidade dos estudos em história do jornalismo a relação das diversas formas de fazer jornalismo (processos jornalísticos) com as características dos contextos em que se encontram (processos históricos), considerando, inclusive, suas dimensões políticas, econômicas e culturais. O início da história da imprensa no Brasil, por exemplo, decorreu da chegada da corte portuguesa ao país, para onde se transferiu em 1808, após fugir da invasão napoleônica que assolava a Europa naquele momento (ROMANCINI; LAGO, 2007).

O cuidado do olhar do pesquisador ajuda a superar esses "obstáculos epistemológicos”, entre eles a ideia de que esses trabalhos se fundamentam em uma visão genérica das práticas sociais (em que tudo é considerado jornalismo), o entendimento de que seu exercício de pesquisa se esgote na mera informação de nomes e datas (impondo-lhe uma tarefa descritiva), interpretação histórica do jornalismo que, às vezes, chega a parecer inerte (não processual), além da manifestação de quaisquer juízos de valor de determinado período histórico em relação a outro (como se uma prática não fosse fruto também de seu tempo).

Nessa estrutura, Marialva Barbosa (2013) elenca aspectos metodológicos para fazer a história do jornalismo. Por um lado, pensar o jornalismo em suas múltiplas extensões (prática profissional, campo de estudos, lugar de saber e disputas de poder, assim como parte de um diálogo com o público). Por outro, considerar as épocas, os processos sociais e as relações humanas (produção de sentidos dos meios de comunicação, em que há o cruzamento de várias subjetividades - a do jornalista, a do público etc.). 
Assim, ao invés de nos determos exclusivamente nas materialidades (as páginas dos jornais), nas gramáticas (o discurso que profere) e na organicidade (as estruturas empresariais, gerenciais e processos produtivos) há que visualizar, sobretudo, os sujeitos envolvidos diretamente nessa história. A história do jornalismo deve ser também uma história das ações humanas (BARBOSA, 2013, p. 7).

O que se espera é que o pesquisador, em sua análise, possa ir além da materialidade dos produtos jornalísticos. E, com efeito, em se tratando da história do jornalismo, alicerçar a relação existente entre o texto (produto jornalístico) e o contexto (processo histórico), formulando conceitos, teorias e métodos. Diante disso, o produto jornalístico em si pode ter muito a dizer, mas, sem o referido contexto histórico, se torna estático, estanque.

Os produtos jornalísticos, aliás, podem nos apresentar marcas e traços dos processos jornalísticos e, consequentemente, dos processos históricos nos quais eles estão inseridos. Essa constatação aparece aqui como uma hipótese de pesquisa, mas tal abordagem já foi desenvolvida em estudos outros (de preocupação metodológica) que buscaram verificar a produção a partir do produto (cf. SILVA, 2008; SILVA; MAIA, 2011; STRELOW ${ }^{5}$, 2007). A discussão vale, obviamente, para os trabalhos em história do jornalismo.

\section{Considerações finais}

Nos últimos anos, os estudos em história do jornalismo têm ganhado bastante ênfase, não só os que se ocupam do estudo dos processos jornalísticos (análise sobre os fenômenos), mas também os que querem pensar esse tipo de pesquisa (reflexões acerca dos modelos teóricos dos dois campos que se entrecruzam: história e jornalismo). Por enquanto, nosso interesse aponta para esta última instância, já que nos propomos a fazer uma "pesquisa da pesquisa".

Buscamos, neste texto, manifestar a história do jornalismo com o olhar voltado para o território de pesquisa do jornalismo. No entanto, ter noção do conjunto de características que formam a identidade do pesquisador desta subárea da Comunicação não é condição necessária para o intento que pretendemos nessa jornada. É uma tarefa

\footnotetext{
${ }^{5} \mathrm{~A}$ autora afirma que os produtos jornalísticos, quando transformados em objetos de análise, "revelam-se vivos e repletos de histórias a serem descobertas por detrás da palavra enunciada" (STRELOW, 2007, p. 1).
} 
contínua, na qual o pesquisador precisa requerer para si o exercício da "vigilância epistemológica" (BACHELARD, 1977; BOURDIEU; CHAMBOREDON; PASSERON, 2010; LOPES, 2005; THIOLLENT, $1982)^{6}$.

Tanto os fenômenos jornalísticos quanto as reflexões a respeito do modo como as pesquisas são realizadas se colocam como potenciais objetos de estudo. Com relação à história do jornalismo, vislumbramos muitas possibilidades. Para isso, um bom começo é firmar a compreensão histórica dos processos jornalísticos, bem como em relação aos conceitos, teorias e métodos do seu campo de pesquisa.

\section{REFERÊNCIAS}

ANUNCIAÇÃO, Cristiano. A história como percurso metodológico para a pesquisa em jornalismo. In: FONSÊCA, Angélica; GERALDES, Elen Cristina; NEGRINI, Vanessa (Orgs.). Em busca da consciência metodológica: limites e possibilidades da pesquisa em comunicação. São Paulo: Baraúna, p. 423-435, 2015.

BACHELARD, Gaston. A epistemologia. Edições 70, 2006.

A formação do espírito científico. Tradução de Estela dos Santos Abreu. Contraponto, 1996.

O racionalismo aplicado. Tradução de Nathanael Caixeiro. Rio de Janeiro: Zahar, 1977.

BARBOSA, Marialva. O método e a análise histórica do jornalismo. In: XXXVI Congresso Brasileiro de Ciências da Comunicação. Anais... Manaus, 2013.

Percursos do Olhar: comunicação, narrativa e memória. Niterói: EdUFF, 2007.

. O que a história pode legar aos estudos de jornalismo. Contracampo. Niterói, v. 12, p. 51-62, 2005.

\footnotetext{
${ }^{6}$ De um modo geral, a vigilância epistemológica diz respeito ao cuidado permanente que o pesquisador deve ter com as condições e os limites das técnicas e dos conceitos utilizados no seu fazer científico.
} 
BARBOSA, Marialva; RIBEIRO, Ana Paula. O que a história pode legar aos estudos em jornalismo? Contracampo. Niterói: Universidade Federal Fluminense, v. 12, p. 51-61, 2005.

BELTRÃO, Luiz. Iniciação à filosofia do jornalismo. São Paulo: Edusp. 2. ed, 1992.

BENJAMIN, Walter. Sobre o conceito da história. In: BENJAMIN, Walter. Magia e técnica, arte e política: ensaios sobre literatura e história da cultura. Tradução de Sergio Paulo Rouanet. São Paulo: Editora Brasiliense. 3. ed. p. 222-232, 1987.

BOURDIEU, Pierre; CHAMBOREDON, Jean-Claude; PASSERON, JeanClaude. Ofício de sociólogo: metodologia da pesquisa na sociologia. Tradução de Guilherme João de Freitas Teixeira. 7. ed. Petrópolis: Vozes, 2010.

FOUCAULT, Michel. As palavras e as coisas: uma arqueologia das ciências humanas. Tradução de António Ramos Rosa. São Paulo: Martins Fontes, 1966.

GROTH, Otto. O poder cultural desconhecido: fundamentos da ciência dos jornais. Tradução de Liriam Sponholz. Petrópolis: Vozes, 2011.

Tarefas da pesquisa da ciência da cultura. In: MAROCCO, Beatriz; BERGER, Christa (Orgs.). A era glacial do jornalismo: teorias sociais da imprensa. Porto Alegre: Sulina, p. 182-306, 2006.

LOPES, Maria Immacolata Vassalo. Pesquisa em comunicação. 9. ed. São Paulo: Edições Loyola, 2005.

MARTINO, Luiz Claudio. Classificação e exame crítico da literatura sobre história da comunicação. In: RIBEIRO, Ana Paula; HERSCHMANN, Micael (Orgs.). Comunicação e história: interfaces e novas abordagens. Rio de Janeiro: Mauad X Globo Universidade, p. 27-43, 2008. 
Apontamentos epistemológicos sobre a fundação e fundamentação do campo da comunicação. In: CAPPARELLI, Sérgio; SODRÉ, Muniz; SQUIRRA, Sebastião (Orgs.). Livro da XIII compós 2004: a comunicação revisitada. Porto Alegre: Sulina, p. 41-66, 2005.

PONTES, Felipe. 25 anos de 'O segredo da pirâmide' - a singularidade como categoria na teoria do jornalismo e na teoria da história: possibilidades para compreender a produção jornalística de acontecimentos. In: $10^{\circ}$ Encontro Nacional de Pesquisadores em Jornalismo. Curitiba. Anais... Curitiba, 2012.

Teoria e história do jornalismo: confluências e divergências das teorias do jornalismo e da história. Interin. Curitiba, v. 10, n. 2, p. 1-23, jul./dez. 2010.

Do jornalismo e da história à história do jornalismo. Estudos em Jornalismo e Mídia. Ano v, n. 2, p. 167-185, jul./dez. 2008.

ROMANCINI, Richard. História e jornalismo: reflexões sobre campos de pesquisa. In: BENETTI, Marcia; LAGO, Cláudia. Metodologia de pesquisa em jornalismo. Petrópolis: Vozes, p. 23-47, 2007.

ROMANCINI, Richard; LAGO, Cláudia. História do jornalismo no Brasil. Florianópolis: Insular, 2007.

SILVA, Gislene. Problemática metodológica em jornalismo impresso. Rumores. São Paulo, v. 2, n. 3, jul./dez. 2008.

SILVA, Gislene; MAIA, Flávia. Análise de cobertura jornalística: um protocolo metodológico. Rumores. São Paulo, v. 10, p. 18-36, jul./dez. 2011.

SOUSA, Jorge Pedro. Uma história breve do jornalismo no ocidente. Biblioteca Online de Ciências da Comunicação, 2008.

STRELOW, Aline. Análise global de processos jornalísticos. In: V Encontro Nacional de Pesquisadores em Jornalismo. Anais... Aracaju, 2007.

THIOLLENT, Michel. Crítica metodológica, investigação social e en- 
quete operária. São Paulo: Polis, 1982.

VEYNE, Paul. Como se escreve a história; Foucault revoluciona a história. Tradução de Alda Baltar e Maria Auxiliadora Kneipp. Brasília: Editora Universidade de Brasília, 4. ed., 2008. 


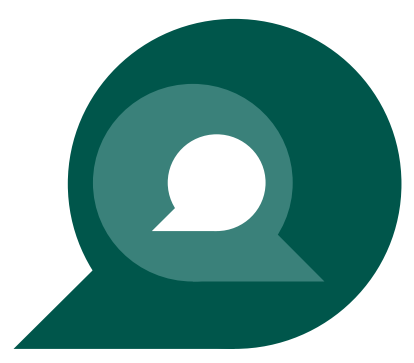

